\title{
Flipped classroom improves the results in Pathophysiology learning: results of a non- randomized controlled study
}

\section{J. Ignacio Herrero ( $\square$ iherrero@unav.es )}

Clinica Universidad de Navarra https://orcid.org/0000-0002-9076-6717

Jorge Quiroga

Clinica Universidad de Navarra

\section{Research article}

Keywords: Medical Education Research, Flipped classroom, Pathophysiology, Gender

Posted Date: May 28th, 2019

DOI: https://doi.org/10.21203/rs.2.9889/v1

License: (c) (1) This work is licensed under a Creative Commons Attribution 4.0 International License.

Read Full License 


\section{Abstract}

Background The flipped classroom has become increasingly popular in health professions education. The aim of this study is to analyze its effect on learning in a Pathophysiology course. Methods Flipped classroom was introduced to teach Respiratory Pathophysiology in 2018. The results obtained in the exam were compared with the results of previous year students and with the evolution in Blood Pathophysiology (given by the same teacher, in a traditional way). Comparisons between groups were done with the Student's T test. A survey was administered to the students after finishing the term. Results 201 students were examined in 2018 (and 229 in 2017). Gender distribution and the qualifications obtained in General Pathology were comparable between them. The results in Respiratory Pathophysiology were significantly better in 2018 than in 2017 (mean: 48 versus 42 over 100; P=0.004), but the results in Blood Pathophysiology were comparable between both groups. The improvement was significant only in students that obtained scores below the median $(P=0.009)$ and was more evident in male than in female students. Most students considered that flipped classroom was more attractive and helped them to learn more and with less effort. Conclusions Flipped classroom increases medical students' knowledge acquisitions in Pathophysiology. It benefits more to male students and those with lower qualifications.

\section{Background}

The flipped classroom (FC) is a student-centered pedagogical approach that is becoming increasingly popular in health professions education. It switches the traditional order of learning, that is initiated by a didactic lecture and is followed by a personal study. In the FC model, students receive the didactic material out of the classroom and discuss with their teacher during the formal teaching time. This approach increases active learning (1). It is aimed to help the students to become critical thinkers and to stimulate a deep understanding (2).

Several investigators have studied the potential effect of FC on learning and on students' satisfaction in health professions education. Two recent meta-analysis have reviewed published studies, obtaining different conclusions. Hew and Lo (3) reviewed the experience in health professions concluding that FC improves learning and is preferred by the students. On the other hand, Gillette et al (4) concluded that FC was associated with minimal gains in students' knowledge compared to lecture in Pharmacy education.

Thus, the aim of this manuscript is to report our initial experience with FC in the teaching of Pathophysiology to third year medical students.

\section{Materials And Methods}

\section{Participants and settings}

Participants were third year medical students from the Universidad de Navarra (Pamplona, Spain). They were students from two consecutive years (219 in 2017-18 and 201 in 2018-19) who were enrolled in 
Pathophysiology course. Pathophysiology is a whole-year course divided in two four-month parts. The first part (September to December) includes cardiovascular, renal, respiratory and blood pathophysiology and the second part (January to April) includes neurological, endocrine and metabolism and liver and gastrointestinal pathophysiology. The faculties of this subject are members of the Department of Internal Medicine. In the first part, one of the staff members (JIH) teaches both Respiratory (RP) and Blood Pathophysiology (BP). At the end of the first part, in December, the students have an exam, and those who pass it with a qualification above 60 out of 100 do not need to be examined of this part in the final exam in May. This exam includes a test with 100 multiple-choice questions ( 25 of every of the four parts). The final score is obtained after subtracting one third of the number of wrong answers to the number of correct answers.

\section{Intervention}

In 2018, a FC method was used to teach RP. Several days before each session, the students received 3-4 videos of 5-7 minutes for each lesson. The videos consisted in the same presentation the teacher gave in the 2017 lectures with the slides used in the lectures. The students were allowed to send an e-mail to the teacher asking for a more detailed explanation of the doubtful points. The schema for every $45-50$ minutes subsequent session was: 1) a 5-minute review of the lesson explained in the last session through 3-4 multiple-choice questions shown by the app Socrative (www.socrative.com); 2) explanation of the lesson of the day (30 minutes), restricted to the students' questions (sent via e-mail or asked in the classroom) and to the most important / difficult concepts according to the teacher's criterion; 3 ) presentation and discussion of a brief clinical case (5-10 minutes); and 4) review of the lesson through the comment of the multiple-choice questions about it that had been included in the last year exam.

The same teacher explained BP, without using videos. The schema of the sessions was similar, but the explanation of the lesson of the day was given in a standard fashion. The students had the slides used for the explanation several days before the session. In 2017, the same teacher explained the same lessons, but all were given in a standard fashion. The results of this year were used as control.

The staff members of the Department of Internal Medicine were also the teachers of General Pathology (GP) in the second year. This four-month course is an introduction to Pathophysiology and is mostly devoted to the explanation of Etiology and Pathogenesis of disease.

\section{Survey}

The students were offered a survey about the FC method. The response to it was voluntary and anonymous. They had six weeks to respond to it, between the end of the sessions and the publication of the results of the December exam, including Christmas holydays.

\section{Ethics statement}

The study was approved by the School of Medicine of the Universidad de Navarra and by the Ethics Committee for Research of the Universidad de Navarra (project 2018-112). Students were not 
compensated for their participation in the study. They did not give their informed consent. Data of the students were recorded in a coded database, without personal information.

\section{Statistical analysis}

All the statistical analyses were done with the software SPSS. For all tests, a P value below 0.05 was considered as statistically significant. Continuous variables are expressed as mean (standard error of mean) and categorical variables as number (percentage). Comparisons between groups were done with the Chi-square test (categorical variables) and Student's t test for independent series (continuous variables).

\section{Results}

In 2017 and 2018, 229 and 201 students were enrolled in the Pathophysiology course and did the December exam, respectively. They were balanced according to their genders and the results they had obtained in GP (Table 1).

Comparison of the results in the control and intervention group.

The results obtained in the December exam in RP and BP are shown in table 2. There was an improvement in the results in RP, but not in BP. The proportion of students that obtained a score above $60 \%$ (the minimum score to pass the December exam) in RP increased from $22 \%$ to $29 \%(P=0.077)$, and decreased from $33 \%$ to $31 \%$ in $\mathrm{BP}(\mathrm{P}=0.757)$.

\section{Effect of the flipped classroom according to the academic results and gender}

With the aim of investigate whether the FC method benefits more to students with better or worse academic level, we divided the classes according to their performance in GP in the previous year (above or below the median). The results in BP did not change in 2018, as compared with the results of 2017. The results in RP after applying the FC significantly improved in students who scored below the median in GP (Table 3).

The improvement in the results in RP was significant in male students, but not in female students (Table 4). The results of male students in RP in 2018 were significantly better than the results of female students. There were no significant differences in the rest of the comparisons between genders neither in 2017 nor in 2018 (Table 5).

\section{Students'survey}

Twenty students responded to the survey about the FC method (Table 6). Eleven (55\%) of them said that it contributed to increasing their interest for the course. Fifteen (75\%) said that this method helped them to increase their learning. Most students expressed that the method made the topic easier to understand, but some of them disliked it because it was more time-consuming and made it necessary to study every 
day the lesson of the day. Seventy-five percent of the students wanted to receive more learning with this method, depending on the teacher and the topic.

\section{Discussion}

The results of this study confirm other authors' results about the positive effect of FC on medical students' learning, as compared with the traditional teaching (5-11). These results have been confirmed in a recently published meta-analysis (3). The FC method of teaching increases active learning (1) and stimulate students to deep understanding (2). Despite all these results, other authors have not found such positive effect on learning (12-14) and a recent meta-analysis in Pharmacy education concluded that flipped classroom is associated with minimal gains in student knowledge compared to lecture (4). This may be due to different methods of flipped teaching used by different authors.

Interestingly, this improvement was found mainly in the students with results that were below the median level of the class. This finding is in agreement with the results of Gross et al. (15). This may be due to a higher availability of learning tools or because FC encourages the students to prepare their classes day to day instead of studying it just before the exams.

Another interesting finding is the different improvement according to genders. We have found a significant improvement with flipped learning only in male students. The results contrast with other authors' findings (15), who found a more evident improvement in female students. On the other hand, Carrick et al. (14) found that women scored higher than men in a traditional classroom environment, but the differences disappeared in the online classroom. Differences between genders have also been found with the use of other teaching methods, like the writing of multiple-choice questions by the students (16). On the same way, the preference of teaching materials is different between genders (17). The differences in the results between genders with the FC may be related to the lack of physical interaction between men and women in the online format, as suggested by Carrick et al. (14) or to the exposition of a broader variety of learning tools, as suggested by Gross et al. (15). Recent studies have found that the learning interests of male and female students are different $(18,19)$.

Other potential benefit of flipped teaching is the improvement of students' attitude. Several authors have found an improvement in this field $(11,12,20)$, and the results of our study agree with them. According to the results of the survey, flipped teaching helped our students to be more interested on the topic and to increase their knowledge. The only drawback was that some students perceived that this learning methodology increased their time dedicated to study and forced them to study in a day-to-day rhythm. Other authors have also found that the students need more study time with the FC method (7).

\section{Limitations of the study}

In our study, a single learner applied the new method in a single university. It may limit the generalizability of the results. Another limitation is the absence of randomization. The results of the intervention group were compared with the results obtained in a historic cohort of students. The improvement in the results 
in the topic that was given as FC and the lack of improvement in the topic explained by traditional lectures suggest that this improvement is due to the new methodology. Finally, the low proportion of respondents to our students survey (10\%) does not allow obtaining a firm conclusion about the students' satisfaction with this new method.

\section{Conclusions}

The use of flipped learning was followed by an improvement in the knowledge. Male students and those with scores below the median seem to benefit more of this learning method.

\section{Abbreviations}

FC: Flipped classroom

RP: Respiratory Pathophysiology

BP: Blood Pathophysiology

GP: General Pathology

\section{Declarations}

Ethics approval and consent to participate

The study was approved by the School of Medicine of the Universidad de Navarra and by the Ethics Committee for Research of the Universidad de Navarra (project 2018-112).

Students were not compensated for their participation in the study. Some of the participants responded to a survey. The response was voluntary and anonymous.

\section{Consent for publication}

Not applicable.

\section{Availability of data and materials}

The datasets used and analysed during the current study are available from the corresponding author on reasonable request.

Competing interests

The authors declare that they have no competing interests.

Funding 
The authors did not receive any funding for this research

\section{Authors' contribution}

Design of the study: JIH and JQ

Preparation of the pedagogical materials for flipped classroom and applying them: $\mathrm{JIH}$

Creation of the database: $\mathrm{JIH}$

Statistical analysis: JIH and JQ

Writing of the manuscript: $\mathrm{JIH}$

Approval of the final version of the manuscript: JIH and JQ.

Acknowledgements

Not applicable

\section{References}

1. Jensen JL, Kummer TA, d M Godoy PD. Improvements from a flipped classroom may simply be the fruits of active learning. CBE Life Sci Educ 2015; 14: ar5.

2. McLaughlin JE, Roth MT, Glatt DM, Gharkholonarehe N, Davidson CA, Griffin LM, et al. The flipped classroom: a course redesign to foster learning and engagement in a health professions school. Acad Med 2014; 89:236-43.

3. Hew KF, Lo CK. Flipped classroom improves student learning in health professions education: a metaanalysis. BMC Med Educ 2018; 18: 38.

4. Gillette C, Rudolph M, Kimble C, Rockich-Winston N, Smith L, Broedel-Zaugg K. A meta-analysis of outcomes comparing flipped classroom and lecture. Am J Pharm Educ 2018; 82: 433-40.

5. O'Connor EE, Fried J, McNulty N, Shah P, Hogg JP, Lewis P, et al. Flipping Radiology education right side up. Acad Radiol 2016; 23: 810-22.

6. Tune JD, Sturek M, Basile DP. Flipped classroom model imporves graduate student performance in cardiovascular, respiratory and renal physiology. Adv Physiol Educ 2013;37:316-20.

7. Rui Z, Liang-rui X, Rong-zheng Y, Jing Z, Xue-hong W, Chuan Z. Friend or foe? Flipped classroom for undergraduate electrocardiogram learning: a randomized controlled study. BMC Med Educ 2017;17:53.

8. Morton DA, Colbert-Getz JM. Measuring the impact of the flipped anatomy classroom: the importance of categorizing an assessment by Bloom's taxonomy. Anat Sci Educ 2017; 10: 170-5. 
9. Lieber CA, Lin DT, Mazer LM, Bereknyei S, Lau JN. Effectiveness of the Surgery core clerckship flipped classroom: a prospective cohort trial. Am J Surg 2016; 211:451-7.

10. Gillispie V. Using the flipped classroom to bridge the gap to generation Y. Oschner J 2016; 16: 32-6.

11. Granero Lucchetti AL, da Silva Ezequiel O, Noceli de Oliveira I, Moreira-Almeida A, Lucchetti A. Using the traditional or flipped classrooms to teach 'Geriatrics and Gerontology'? Investigating the impact of active learning on medical students' competences. Medical Teacher 2018; 40:1248-56.

12. Ilic D, Nordin RB, Glasziou P, Tilson JK, Villanueva E. A randomized controlled trial of a blended learning education intervention for teaching evidence-based medicine. BMC Med Educ 2015;15:39.

13. Street SE, Gilliland KO, McNeil C, Royal K. The flipped classroom improved medical student performance and satisfaction in a pre-clinical Physiology course. Med Sci Educ 2015; 25:35-43.

14. Carrick FR, Abdulrahman M, Hankir A, Aayruzny M, Najem K, Lungchukiet $P$, et al. Randomized controlled study of a remote flipped classroom Neuro-otology curriculum. Front Neurol 2017; 8: 349.

15. Gross D, Pietri ES, Anderson G, Moyano-Camihort K, Graham MJ. Increased preclass preparation underlies student outcome improvement in the flipped classroom. CBE Life Sci Educ 2015; 14: ar36.

16. Herrero JI, Lucena F, Quiroga J. Randomized study showing the benefit of medical students writing multiple choice questions on their learning. BMC Med Educ 2019; 19: 72.

17. Benditz A, Pulido L, Renkawitz T Schwarz T, Grifk J, Weber M. Are there gender-dependent study habits in times of the world wide web?. Biomed Res Int 2018; 2018: 3196869.

18. Nebeker CA, Basson MD, Haan PS, Davis AT, Ali M, Gupta RN, et al. Do female surgeons learn or teach differently?. Am J Surg 2017; 213:282-7.

19. Ali A, Subhi Y, Ringsted C, Konge L. Gender differences in the acquisition of surgical skills: a systematic review. Surg Endosc 2015; 29: 3065-73.

20. Hsu S-D, Chen C-J, Chang W-K, Hu Y-J. An investigation of the outcomes of PGY students' cognition of and persistent behavior in learning through the intervention of the flipped classroom in Taiwan. PLOS One 2016; 11: e0167598.

\section{Tables}

Table 1. Basal comparison of both groups of students 


\begin{tabular}{llll} 
& 2017 (control) & 2018 (flipped) & $P$ \\
\hline Gender & $73(32 \%)$ & $78(39 \%)$ & 0.156 \\
Male & $156(68 \%)$ & $123(61 \%)$ & \\
Female & & & \\
\hline Results in General Pathology* & $58.9(0.9)$ & $59.2(0.9)$ & 0.830
\end{tabular}

* over 100

Table 2. Comparison of the results obtained in Respiratory and Blood Pathophysiology in the control and in the intervention group*.

\begin{tabular}{llll} 
& 2017 (control) & 2018 (flipped) & P \\
\hline Blood Pathophysiology & $48.8(1.4)$ & $47.9(1.4)$ & 0.649 \\
\hline Respiratory Pathophysiology & $42.1(1.4)$ & $48(1.5)$ & 0.004
\end{tabular}

*over 100

Table 3. Evaluation of the impact of flipped classroom in Respiratory Pathophysiology teaching in students above and below the median in General Pathology*.

\begin{tabular}{|c|c|c|c|}
\hline & 2017 (control) & 2018 (flipped) & $\mathrm{P}$ \\
\hline Blood Pathophysiology & $39.4(1.8)$ & $38.2(2.0)$ & 0.647 \\
\hline Above median & $59.5(1.8)$ & $58.1(1.8)$ & 0.573 \\
\hline Respiratory Pathophysiology & $32.9(1.7)$ & $39.8(1.9)$ & 0.009 \\
\hline Above median & $53.5(1.9)$ & $57.2(2.2)$ & 0.200 \\
\hline
\end{tabular}

*over 100.

Table 4. Evaluation of the impact of flipped classroom in the teaching of Respiratory Pathophysiology according to gender*. 
2017 (control) 2018 (flipped) P

\begin{tabular}{llll} 
Blood Pathophysiology & $52.0(2.3)$ & $48.7(2.1)$ & 0.301 \\
Male & $47.4(1.7)$ & $47.5(1.9)$ & 0.981 \\
Female & & & \\
\hline Respiratory Pathophysiology & $44.1(2.4)$ & $52.5(2.1)$ & 0.010 \\
Male & $41.1(1.7)$ & $45.2(2.0)$ & 0.125 \\
Female & & &
\end{tabular}

*over 100

Table 5. Comparison in the academic results between male and female students.*

\begin{tabular}{llll} 
& Male & Female & $P$ \\
\hline 2017 & $58.3(1.7)$ & $59.2(1.0)$ & 0.638 \\
General Pathology & $52.0(2.3)$ & $47.4(1.7)$ & 0.131 \\
Blood & $44.1(2.4)$ & $41.1(1.7)$ & 0.324 \\
Respiratory & & & \\
\hline 2018 & $59.9(1.5)$ & $58.7(1.2)$ & 0.534 \\
General Pathology & $48.7(2.1)$ & $47.5(1.9)$ & 0.670 \\
Blood & $52.5(2.1)$ & $45.1(2.0)$ & 0.014 \\
Respiratory & & &
\end{tabular}

*over 100

Table 5. Comparison in the academic results between male and female students.* 


\begin{tabular}{llll} 
& Male & Female & $P$ \\
\hline 2017 & $58.3(1.7)$ & $59.2(1.0)$ & 0.638 \\
General Pathology & $52.0(2.3)$ & $47.4(1.7)$ & 0.131 \\
Blood & $44.1(2.4)$ & $41.1(1.7)$ & 0.324 \\
Respiratory & & & \\
\hline 2018 & $59.9(1.5)$ & $58.7(1.2)$ & 0.534 \\
General Pathology & $48.7(2.1)$ & $47.5(1.9)$ & 0.670 \\
Blood & $52.5(2.1)$ & $45.1(2.0)$ & 0.014 \\
Respiratory & & &
\end{tabular}

*over 100

Table 6. Results of the survey about the flipped learning (20 respondents).

\begin{tabular}{lllc} 
& Agree & $\begin{array}{l}\text { Neither agree nor } \\
\text { disagree }\end{array}$ & Disagree \\
\hline Flipped method is more enjoyable & $\begin{array}{l}12 \\
(60 \%)\end{array}$ & $7(35 \%)$ & $1(5 \%)$ \\
\hline Flipped method increases interest & $\begin{array}{l}11 \\
(55 \%)\end{array}$ & $7(35 \%)$ & $2(10 \%)$ \\
\hline Flipped method increases learning & $\begin{array}{l}15 \\
(75 \%)\end{array}$ & $5(25 \%)$ & $0(0 \%)$ \\
\hline Flipped method decreases the effort of learning & $\begin{array}{l}14 \\
(70 \%)\end{array}$ & $4(20 \%)$ & $2(10 \%)$ \\
\hline $\begin{array}{l}\text { Flipped method should substitute lectures (partially } \\
\text { or totally) }\end{array}$ & $\begin{array}{l}15 \\
(75 \%)\end{array}$ & $0(0 \%)$ & $5(25 \%)$ \\
\hline
\end{tabular}

